\title{
Formation of block-copolymer-templated mesoporous silica
}

Emma M. Björk ${ }^{1,2 *}$, Peter Mäkie ${ }^{1}$, Lina Rogström $^{1}$, Aylin Atakan $^{1}$, Norbert Schell $^{3}$ and Magnus Odén ${ }^{1}$

${ }^{1}$ Nanostructured Materials, Dept. of Physics, Chemistry, and Biology, Linköping University, 58183 Linköping, Sweden

${ }^{2}$ Institute of Inorganic Chemistry II, University of Ulm, Albert-Einstein-Allee 11, 89081 Ulm, Germany

${ }^{3}$ Helmholtz-Zentrum Geesthacht, Max-Planck-Str. 1, 21502 Geesthacht, Germany

\section{Corresponding Author}

*Emma Björk

E-mail: emma.bjork@liu.se

Phone: +46 13282543

Fax: +461328 8918 


\begin{abstract}
In situ attenuated total reflectance Fourier transform infrared spectroscopy is used to monitor the chemical evolution of the mesoporous silica SBA-15 from hydrolysis of the silica precursor to final silica condensation after the particle formation. Two silica precursors, tetraethyl orthosilicate (TEOS) or sodium metasilicate (SMS) were used, and the effects of additive (heptane and $\mathrm{NH}_{4} \mathrm{~F}$ ) concentrations were studied. Five formation stages are identified when TEOS is used as the precursor. The fourth stage correlates with the appearance and evolution of diffraction peaks recorded using in situ small angle x-ray diffraction. Details of the formed silica matrix are observed, e.g. the ratio between six-fold cyclic silica rings and linear bonding increases with the $\mathrm{NH}_{4} \mathrm{~F}$ concentration. The TEOS hydrolysis time is independent of the $\mathrm{NH}_{4} \mathrm{~F}$ concentration for small amounts of heptane, but is affected by the size of the emulsion droplets when the heptane amount increases. Polymerization and condensation rates of both silica precursors are affected by the salt concentration. Materials synthesized using SMS form significantly faster compared to TEOS-materials due to the pre-hydrolysis of the precursor. The study provides detailed insights into how the composition of the synthesis solution affects the chemical evolution and micellar aggregation during formation of mesoporous silica.
\end{abstract}

\title{
Keywords
}

Mesoporous silica, SBA-15, formation, silica precursor, in situ ATR, in situ SAXRD. 


\section{Introduction}

Mesoporous materials are today used in several applications, e.g. drug delivery, ${ }^{1}$ sensing, ${ }^{2}$ and catalysis. ${ }^{3}$ To optimize the materials performance, it is necessary to tune the materials characteristics. Mesoporous silica of SBA-15 type, ${ }^{4}$ has with its flexible pore size and controllable morphology been a popular choice for these purposes. However, information regarding the material formation is crucial for controlling the material characteristics, e.g. intrawall porosity, ${ }^{5}$ surface silanol content, ${ }^{6}$ and for growth of mesoporous films on substrates. ${ }^{7}$

The SBA-15 is synthesized through a sol-gel process, where a silica precursor is added to an acidic micellar solution. The silica walls are formed around the micelles followed by hydrothermal treatment at elevated temperatures, and finally, the surfactants are removed by calcination or chemical extraction to yield the mesoporous material. ${ }^{4}$ The formation can be described by three, sometimes overlapping, periods: the micellar period, the micellar-to-structured material period, and the particle development period. ${ }^{8}$ Even though several different analysis techniques have been applied, such as X-ray and neutron scattering, ${ }^{9-11}$ nuclear magnetic resonance (NMR), ${ }^{12-13}$ electron paramagnetic resonance spectroscopy (EPR),${ }^{14}$ and cryo transmission electron microscopy, ${ }^{13,}{ }^{15}$ there is no consensus on how SBA-15 is formed. The discrepancy is mainly in the second period, regarding how the micelles interact with each other to form the ordered material. One proposed mechanism is where spherical micelles are elongated to non-interacting, cylindrical, silicated micelles, followed by aggregation to larger domains with hexagonal packing. ${ }^{15-17}$ Another study suggests that the spherical micelles aggregate into flocs of spherical micelles and that these form cylindrical micelles that rearrange into the hexagonal structure. ${ }^{18}$ However, the synthesis conditions have varied for the different studies, for example which surfactant and silica precursor that were used, reaction temperature etc. A correlation between the synthesis conditions and micellar evolution is also lacking. Attenuated total reflectance Fourier transform infrared (ATR-FTIR, from here on simple recalled as ATR) spectroscopy has previously been overlooked, as an in situ technique to study the formation of mesoporous silica, due to large water representation, ${ }^{19}$ and instead Raman spectroscopy has been favored. However, using ATR enables observation of the silica evolution also after the formation of particle aggregates, which is something not possible with Raman spectroscopy. ${ }^{19,11}$ Tejedor-Tejedor et al. ${ }^{20}$ showed that ATR is suitable for monitoring the hydrolysis of TEOS, and it has also been used to study the formation of mesoporous films in dip coating. ${ }^{21-23}$ To our knowledge, the presented study is the first to follow the formation of mesoporous particles using in situ ATR.

Low temperature syntheses have been shown to favor large pore SBA-15, and fluoride ions to control the particle morphology, where the particles becomes more narrow when the $\mathrm{F}^{-}$concentration increases. $^{24-27}$ To enable the formation of ordered materials, swelling agents such as alkanes ${ }^{24,28}$ or TIPB $^{26}$ have been used. Furthermore, it has been shown that $\mathrm{F}^{-}$ions affect the formation rate of mesoporous 
silica, even though the formation path is unclear. ${ }^{24}$ Manet et $a l .{ }^{29}$ showed by small angle x-ray scattering (SAXS) that $\mathrm{P} 123$ micelles at $20^{\circ} \mathrm{C}$ are spherical, also in the presence of TMB as a swelling agent, but how the structure evolves to form SBA-15 remains to be illuminated.

An alternative to use orthosilicates as silica precursor is the cheaper sodium metasilicate (SMS).$^{30-31}$ Materials synthesized with SMS exhibit a smaller mesopore size and thicker silica walls compared to when TEOS is used as the precursor. ${ }^{30}$ This indicates a different (unknown) interaction with the micelles. However, the formation of mesoporous silica synthesized with SMS has not been studied in situ previously.

In the presented study, the formation of mesoporous silica at $20^{\circ} \mathrm{C}$ and the effect of additives, $\mathrm{NH}_{4} \mathrm{~F}$ and heptane, as well as silica precursor, TEOS and SMS, are investigated using in situ ATR and in situ small angle x-ray diffraction (SAXRD). The ATR provides chemical data during the entire formation process, from addition of the silica precursor to the final condensation in the formed particles. The detailed information about the species present has not been provided by other characterization methods previously and resolves the effect of each reagent. Information regarding the formation kinetics is also obtained. By using the same set up, just exchanging the analysis cell, studies using different techniques during the exact same synthetic conditions are enabled. Hence, it is possible to combine the structural information from SAXRD with chemical information from ATR to understand the formation path of mesoporous silica.

\section{Materials and methods}

\section{Synthesis}

Hydrochloric acid (purity $\geq 37 \%$, Fluka), triblock copolymer EO20PO70EO20 (P123) (Aldrich), tetraethyl orthosilicate (TEOS) (reagent grade 98\%, Aldrich), heptane (99\%, Sigma-Aldrich), ammonium fluoride ( $\geq 98.0 \%$, Fluka), and sodium metasilicate (SMS) (Aldrich) were used as received.

In a typical synthesis, $2.4 \mathrm{~g}$ of $\mathrm{P} 123$ and a given amount of $\mathrm{NH}_{4} \mathrm{~F}$ was dissolved in $80 \mathrm{~mL} 1.84 \mathrm{M} \mathrm{HCl}$ solution. The mixture was kept at $20{ }^{\circ} \mathrm{C}$ and stirred until the polymer was dissolved. A specified volume of heptane was premixed with $5.5 \mathrm{~mL}$ TEOS and added to the micellar solution. This time point is defined as $t=0$. The synthesis was stirred for 4 minutes and then kept under static conditions at 20 ${ }^{\circ} \mathrm{C}$ until the end of the measurement. The resulting material was filtered and dried at room temperature. For the materials synthesized with SMS, $10 \mathrm{~mL}$ of the total $80 \mathrm{~mL} 1.84 \mathrm{M} \mathrm{HCl}$ was used to dissolve $3.01 \mathrm{~g}$ SMS. The SMS solution and the heptane were not premixed but added simultaneously to the micellar solution. The molar ratios for all reagents were: $\mathrm{P} 123: \mathrm{HCl}: \mathrm{H}_{2} \mathrm{O}$ :heptane: $\mathrm{NH}_{4} \mathrm{~F}$ :silica precursor 1:353:10325:X:Y:60 where $16 \leq X \leq 280$, and $0 \leq Y \leq 1.8$. The obtained materials are labeled: 
Silica precursor_XH_YF, e.g. TEOS_16H_0.9F, where H and F stands for heptane/P123 and $\mathrm{NH}_{4} \mathrm{~F} / \mathrm{P} 123$ molar ratios, respectively.

\section{Characterization}

In situ SAXRD experiments were performed at beamline P07 at PETRA III using a $50.0 \mathrm{keV}$ ( $\lambda=0.248 \AA$ ) $\mathrm{x}$-ray beam. The experimental setup is illustrated in Figure 1. The sample solution was peristaltically pumped through a quartz capillary with an inner diameter of $5.0 \mathrm{~mm}$, and a wall thickness of $1 \mathrm{~mm}$, with a pumping speed of $170 \mathrm{~mL} / \mathrm{min}$. The solution was transported through a Fluran tube with an inner diameter of $4.8 \mathrm{~mm}$. The $\mathrm{x}$-rays were transmitted through the capillary and detected on a 2-dimentional Perkin Elmer detector $\left(200^{2} \mu \mathrm{m}^{2}\right.$ pixel size; $2048 \times 2048$ pixels $)$. The sample-todetector distance was $12213 \mathrm{~mm}$, as determined from measurements of a NIST $\mathrm{LaB}_{6}$ reference sample. A $2 \mathrm{~mm}$ beam-stop was used in front of the detector to avoid damage. The time $t=0$ is defined as the time when the silica precursor is added to the micellar solution. The 2D data was integrated to get onedimensional lineouts. The peak position and the integrated intensity was extracted from the 1D data by fitting pseudo-Voigt functions to the data. Distilled water was used as background.

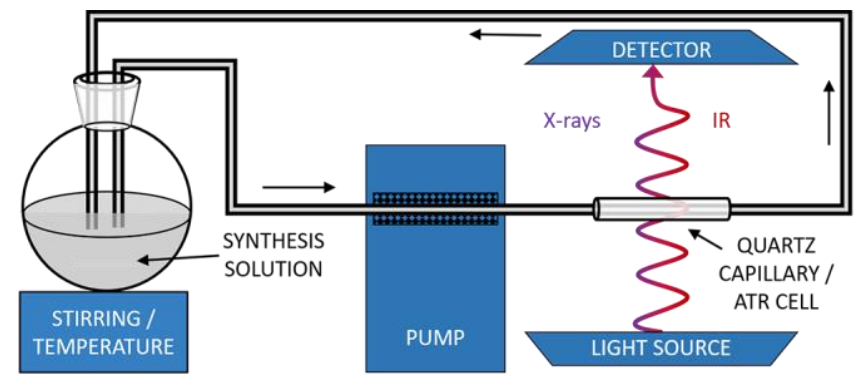

Figure 1. Illustration of the setup used for in situ SAXRD and ATR measurements.

In situ ATR-FTIR was also performed with the setup illustrated in Figure 1, similar to SAXRD but with an ATR cell (Pike Technology). ATR was conducted in a flow-through liquid cell, using a Ge crystal providing 20 internal reflections at $45^{\circ}$ angle of incidence. Distilled water was used as background and each spectrum was an average of 32 scans at $4 \mathrm{~cm}^{-1}$ resolution. The FTIR spectrometer was a Bruker Vertex 70 equipped with a $\mathrm{LN}_{2}$ cooled broad-band mercury cadmium telluride detector and a water cooled glowbar mid-infrared source.

\section{Results}

Kinetics of the TEOS hydrolysis 
The evolution of the silica species and the aggregation of micelles were studied using in situ ATR. For the materials synthesized with TEOS, the initial minutes after the addition of the silica precursor $(t=$ 0) are used to hydrolyze TEOS to form silicic acid and ethanol, c.f. Eq. 1.

$$
\equiv \mathrm{Si}-\mathrm{OR}+\mathrm{H}_{2} \mathrm{O} \rightarrow \equiv \mathrm{Si}-\mathrm{OH}+\mathrm{ROH}
$$

The assignments of bands corresponding to TEOS and ethanol are presented in Table 1, and the ATR spectra of pure references are available in Supporting information S1. Hydrolyses of TEOS in synthesis solutions containing various $\mathrm{NH}_{4} \mathrm{~F}$ and heptane concentrations are presented in Figure 2. Figure 2 (a) shows spectra from a synthesis solution at $t=0-5 \mathrm{~min}$, representative for the initial evolution of all TEOS samples. To follow the hydrolysis of TEOS, the evolution of unique ethanol bands at 880 $\mathrm{cm}^{-1}, 1048 \mathrm{~cm}^{-1}$ and $1088 \mathrm{~cm}^{-1}$, were monitored by plotting the integrated peak areas. It is apparent that all peaks attributed to ethanol increase, while the water peak at $1630 \mathrm{~cm}^{-1}$ decreases because of water consumption in the hydrolysis process. No TEOS-peaks can be detected in the spectrum. This is probably due to a delay when pumping the synthesis solution to the ATR cell, causing TEOS to hydrolyze in the pumping tube prior to reaching the cell, combined with overlaps of the characteristic TEOS peaks at $1168 \mathrm{~cm}^{-1}$ and $960 \mathrm{~cm}^{-1}$ with the bands related to new silica species.
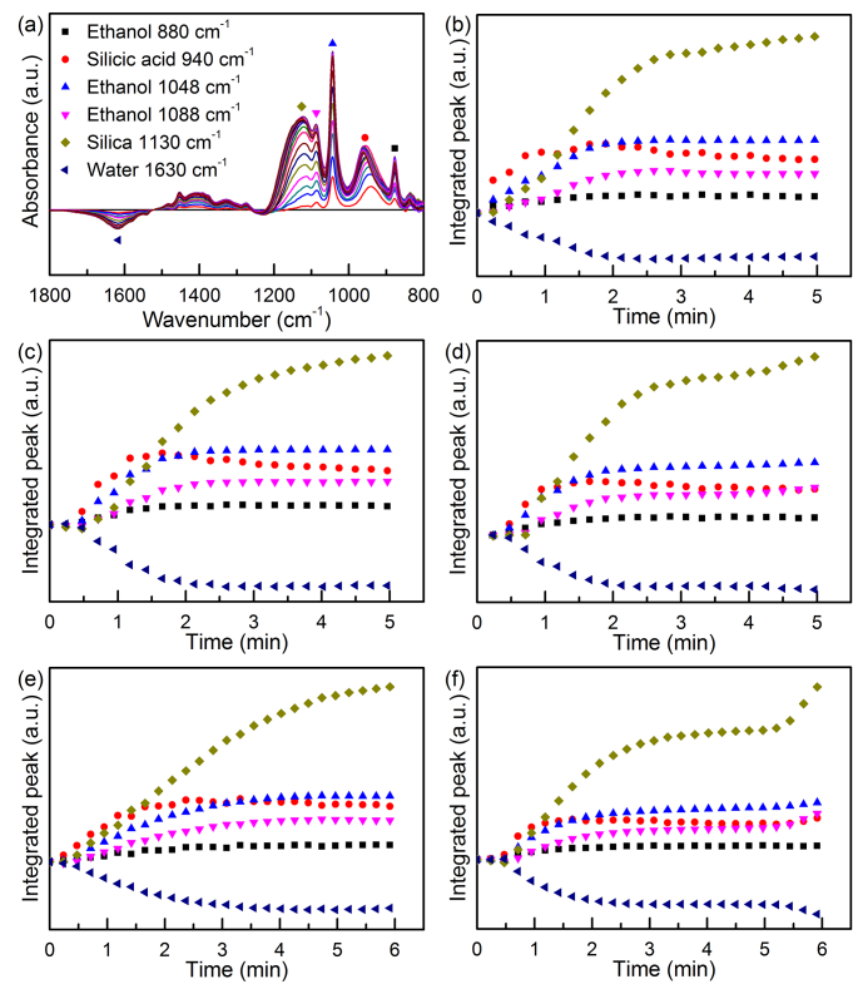

Figure 2. ATR spectra of the synthesis solution at (a) $t=0-5 \mathrm{~min}$, and the evolution of bands related to the hydrolysis of TEOS for (b) TEOS_16H_0.0F, (c) TEOS_16H_0.9F, (d) TEOS_16H_1.8F, (e) TEOS_280H_0.4F, and (f) TEOS_280H_1.8F. 
As can be seen in Figure 2 (b)-(d), all samples synthesized with a heptane to P123 molar ratio of 16 have the same hydrolysis rate, where the band evolution is terminated at $2.5 \mathrm{~min}$, followed by static water and ethanol peaks, indicating that the hydrolysis of TEOS is completed, which corresponds well with the results from Manet et al. ${ }^{11}$. The time to complete the hydrolysis is independent of the $\mathrm{NH}_{4} \mathrm{~F}$ concentration when low heptane amounts are used. When a heptane to P123 molar ratio of 280 is used, the hydrolysis is completed after 4.5 min for TEOS_280H_0.4F, and 2.8 min for TEOS_280H_1.8F. The broad peak at $1130 \mathrm{~cm}^{-1}$ (silica) continues to increase even after hydrolysis completion due to the formation of a silica network.

The peak at $\sim 950 \mathrm{~cm}^{-1}$ (Figure 2 (a)) shifts, in the first $5 \mathrm{~min}$, from $940 \mathrm{~cm}^{-1}$ to $958 \mathrm{~cm}^{-1}$. The peak is initially attributed to monomeric silicic acid as the product of TEOS hydrolysis, but as the condensation of the silica network is initiated, these monomers will bond and form three-dimensional $\mathrm{SiO}_{2}$ with silanol vibrations at $970 \mathrm{~cm}^{-1}{ }^{20}$

\section{Formation of the silica network}

After the first $2.5 \mathrm{~min}$, the hydrolysis of TEOS is completed and free silicic acid is available to form the silica network. This evolution was monitored with ATR, and the peak evolution for TEOS_16H_0.0F is presented in Figure 3. This material was chosen for representation since it forms slowly, which allow for fine details to be observed.
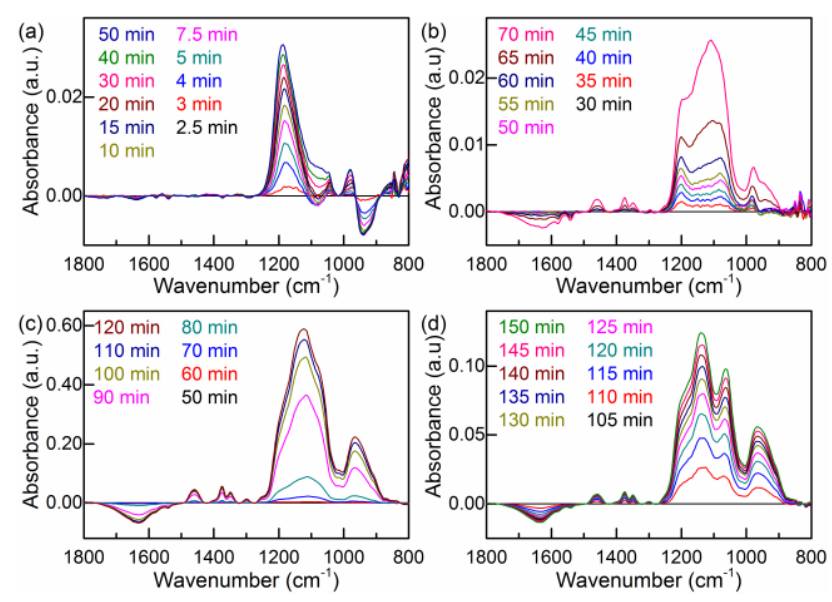

Figure 3. Differential ATR spectra for TEOS_16H_0.0F showing the band evolution during the time periods: (a) 2.5-50 $\mathrm{min}$, (b) 30-70 $\mathrm{min}$, (c) 50-120 min, and (d) 105-150 min.

Figure 3 (a) shows that the silicic acid band $\left(940 \mathrm{~cm}^{-1}\right)$ decreases to a constant value during the first 15 min. Simultaneously, growth is seen for the bands at $980 \mathrm{~cm}^{-1}, 1044 \mathrm{~cm}^{-1}$, and $\sim 1180 \mathrm{~cm}^{-1}$, corresponding to silanols, chain/sheet silica, and Si-O-Si asymmetric stretching, respectively (Table 2). This shows that during the first 20 minutes after the TEOS hydrolysis, the only activity in the synthesis solution is the formation of silica clusters. After $20 \mathrm{~min}$, a broad shoulder appears at $\sim 1080 \mathrm{~cm}^{-1}$, 
revealing the formation a three-dimensional, cyclic silica network. To resolve the following step in the reaction, the spectrum of the $t=30 \mathrm{~min}$ is used as background and subtracted in the spectra shown in Fig. 3 (b). After $30 \mathrm{~min}$, a broad band at $1025-1265 \mathrm{~cm}^{-1}$, corresponding to formation of various silica species, increases. After $55 \mathrm{~min}$, the growth rate of the silica bands strongly increases, accompanied by an evolution of smaller bands at $930 \mathrm{~cm}^{-1}, 1348 \mathrm{~cm}^{-1}, 1374 \mathrm{~cm}^{-1}$, and $1458 \mathrm{~cm}^{-1}$. These peaks are all related to $\mathrm{CH}_{2}$ vibrations in the PPO part of the micelle, see Table $1 .{ }^{32}$ To observe the rapid band growth in more detail, the $t=50 \mathrm{~min}$ spectrum was subtracted to the spectra shown in Figure 3 (c). This figure shows that rapid silica growth occurs for all silica related bands, with a preferential growth of linear structures $\left(1147 \mathrm{~cm}^{-1}\right)$. The growth of PPO related bands follows the evolution of silica. The final stage of the material formation, i.e. the final condensation, is presented in Figure 3 (d). When the growth rate of the silica band decreases, only three bands around $1065 \mathrm{~cm}^{-1}, 1140 \mathrm{~cm}^{-1}$, and $1190 \mathrm{~cm}^{-1}$ continue to grow. These can be attributed to the six-fold and linear asymmetric Si-O-Si stretches, see Table 2. The growth of these bands is the last change seen by ATR.
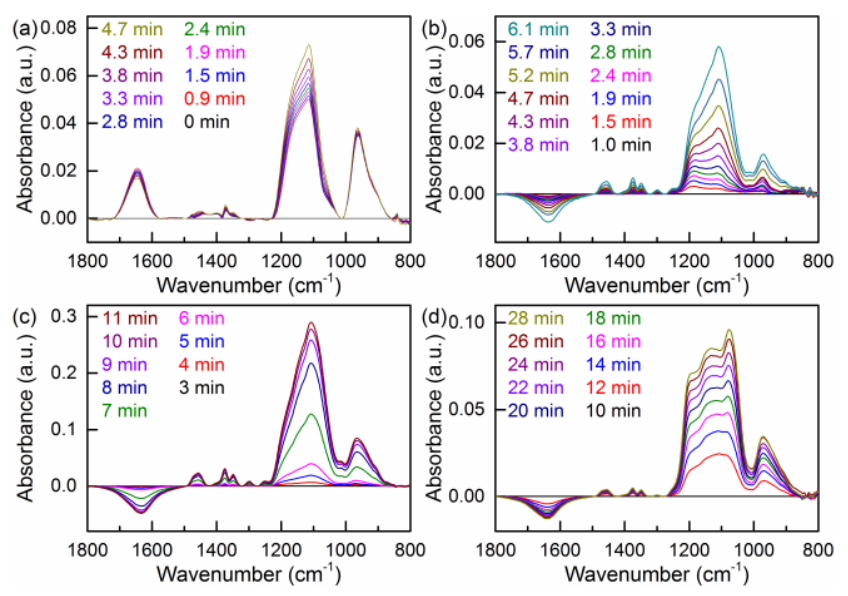

Figure 4. Differential ATR spectra for SMS_16H_0.4F showing the band evolution during the time periods: (a) $0-4.7 \mathrm{~min}$, (b) $1-6.1 \mathrm{~min}$, (c) $3-11 \mathrm{~min}$, and (d) $10-28 \mathrm{~min}$.

The analysis of the formation evolution of materials synthesized with SMS was performed on SMS_16H_0.4F, since SMS_16H_0.0F showed instabilities in the formation, both during the ATR and SAXRD analysis. Figure 4 (a) shows a broad band between $1000-1200 \mathrm{~cm}^{-1}$ corresponding to various silica vibrations, indicating the presence of silica clusters, alongside with the $\mathrm{Si}-\mathrm{OH}$ vibration at $960 \mathrm{~cm}^{-1}$, and the water band at $1630 \mathrm{~cm}^{-1}$ directly after the SMS addition. The increased intensity of the water band is a result of using an aqueous solution for the pre-hydrolysis of the silica precursor. Figure 4 (b) shows the material evolution starting at $1 \mathrm{~min}$ after the addition of the SMS. It is observed that the growth of the broad silica band starts as soon as the SMS has been added to the micllar solution. After $3 \mathrm{~min}$, the silica band growth increases rapidly and, similar as for the TEOS materials, the PPO related bands evolve in the same manner. The final stage of the material formation, after the rapid silica band growth, again consists of an increase of three silica bands. The bands are the same as in the 
final stage for TEOS_16H_0.0F (Figure 3 (d)), but the fraction of six-fold cyclic species $\left(1070 \mathrm{~cm}^{-1}\right.$ and $\left.1190 \mathrm{~cm}^{-1}\right)$ compared to linear structures $\left(1140 \mathrm{~cm}^{-1}\right)$ is larger.

All produced materials show the same ATR patterns as those presented in Figure 3 and Figure 4 for TEOS and SMS respectively, but with different formation kinetics. Figure 5 presents a summary of the formation stages determined from in situ ATR measurements for materials synthesized with a heptane to P123 molar ratio of 16 . The materials synthesized with TEOS (Figure 5 (a)) have five formation stages: (i) TEOS hydrolysis, (ii) silica polymerization, (iii) siliceous network formation, (iv) silica densification, and (v) continued condensation. It is clearly visible that the times for stage (ii) - (v) depend on the $\mathrm{NH}_{4} \mathrm{~F}$ concentration, while the time for the TEOS hydrolysis is constant. For the material synthesized with SMS, there are three stages, identical to stage (iii) - (v) for the TEOS materials (Figure 5 (b)). Naturally, there is no hydrolysis step for the SMS, since the precursor is already added in a hydrolyzed state. Polymerization has also occurred to a large extent prior to the addition to the micellar solution, see Figure 4, which explains why this stage is not observed for the SMS materials. The squares in Figure 5 correspond to the appearance of the first Bragg peak from the SAXRD measurements. From this it is clear that stage (iv) is correlated to the formation of an ordered hexagonal phase of the material. We noted, similar to Baccile et $a l .{ }^{19}$, that the synthesis solution turned milky white at the same time as the appearance of the first Bragg peak. Therefore, we have assigned the formation of hexagonal structure for SMS_16H_1.8F to $1 \mathrm{~min}$, even though the first available data point is recorded later.
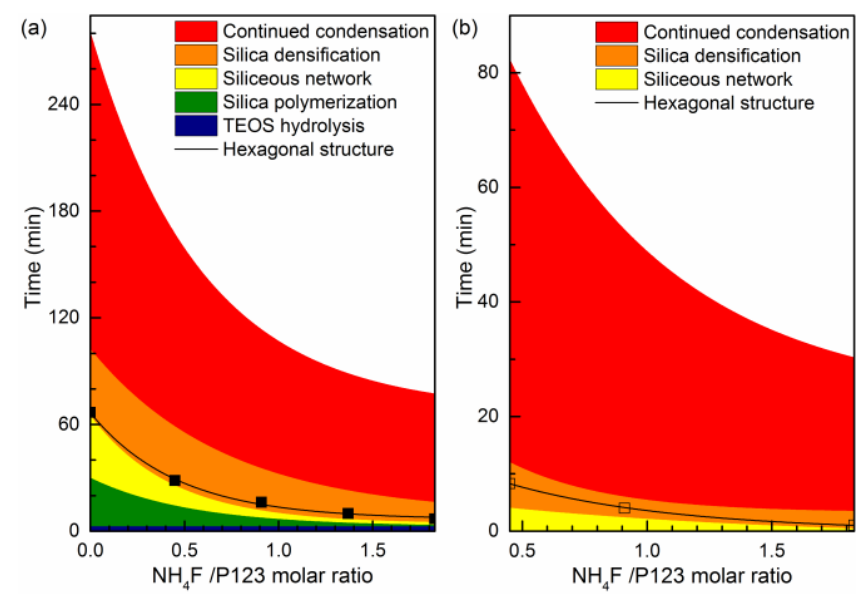

Figure 5. The different stages during the silica formation as a function of $\mathrm{NH}_{4} \mathrm{~F}$ concentration for (a) TEOS and (b) SMS as silica precursors.

\section{Formation of the hexagonal phase}

Figure 6 shows the correlation between the formation stages determined by ATR and the evolution of the 100 Bragg peak from the hexagonally ordered micelles using in situ SAXRD. The 100 peak appears a few minutes into the silica densification stage (iv). The 100 peak shifts rapidly towards larger 
angles (smaller d-spacing), indicating shrinkage of the hexagonal structure upon silica condensation. Simultaneously, the peak intensity increases, verifying that the amount of the hexagonal phase increases. For the materials synthesized with TEOS as the silica precursor (Figure 6 (a), (c), and (e)), the formation of the hexagonal structure mainly occurs during the silica densification stage, where the 100 peak reaches $\sim 80 \%$ of its final intensity. Also, the most distinct shrinkage of the unit cell occurs during stage (iv). This is followed by a slower unit cell shrinkage during stage (v), even after that the peak has reached its maximum intensity. Materials synthesized with SMS (Figure 6 (b) and (d)) show a similar behavior, where the 100 peak appears a few minutes into the silica densification stage. However, this stage is very short for SMS materials, and the structural progression continues well into the final stage of the materials formation.
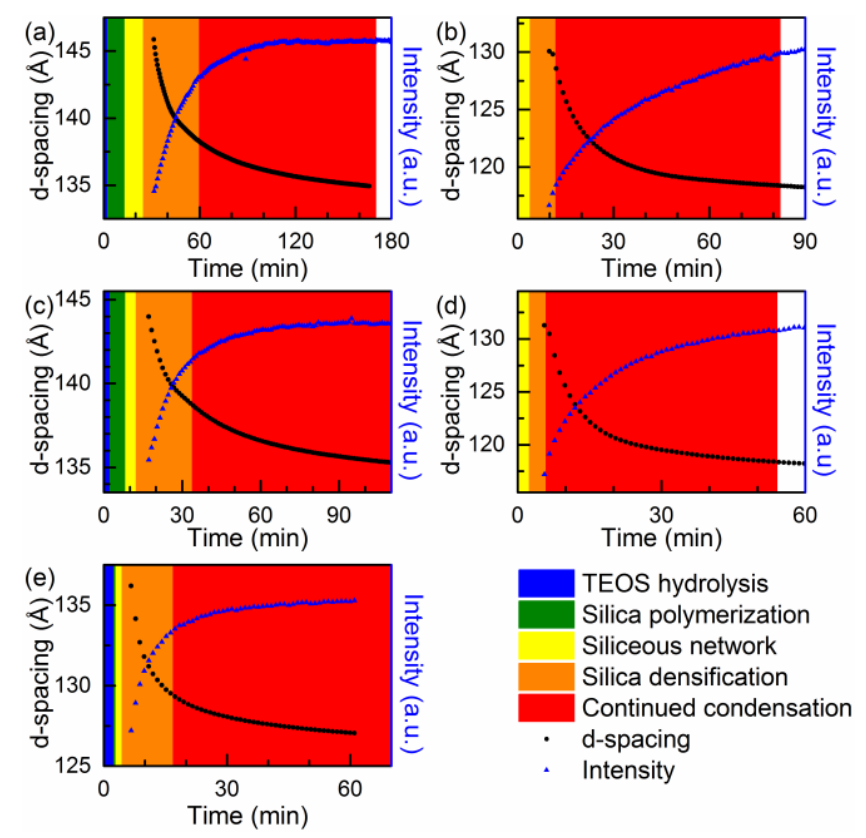

Figure 6. The correlation between the silica formation and evolution of the 100 Bragg peak in (a)

$$
\begin{aligned}
& \text { TEOS_16H_0.4F, (b) SMS_16H_0.4F, (c) TEOS_16H_0.9F, (d) SMS } 16 \mathrm{H} \_0.9 \mathrm{~F} \text {, and (e) } \\
& \text { TEOS_16H_1.8F. }
\end{aligned}
$$

\section{The silica structure as function of $\mathrm{NH}_{4} \mathrm{~F}$ concentration}

The final ATR spectrum of each material is presented in Figure 7. It is apparent that when TEOS is used as silica precursor, the maximum peak intensity is shifted from $1134 \mathrm{~cm}^{-1}$ to $1083 \mathrm{~cm}^{-1}$ as the $\mathrm{NH}_{4} \mathrm{~F}$ concentration is increased (Figure 7 (a) and (c)). This shift occurs independently of the heptane amount. Considering the different silica species possible, this indicate that the materials synthesized with a higher $\mathrm{NH}_{4} \mathrm{~F}$ concentration contains more of the cyclic silica species compared to the materials synthesized with no or low salt amounts, see Table 2, which is also confirmed in Figure 8. The trend is not as visible for materials synthesized with SMS as silica precursor (Figure 7 (b)). A slight broaden- 
ing can be observed when $\mathrm{NH}_{4} \mathrm{~F}$ is introduced, but the maximum band intensity is located at a constant wavenumber $\left(1113 \mathrm{~cm}^{-1}\right)$. The wavenumber shifts for all materials are presented in Figure 7 (d).
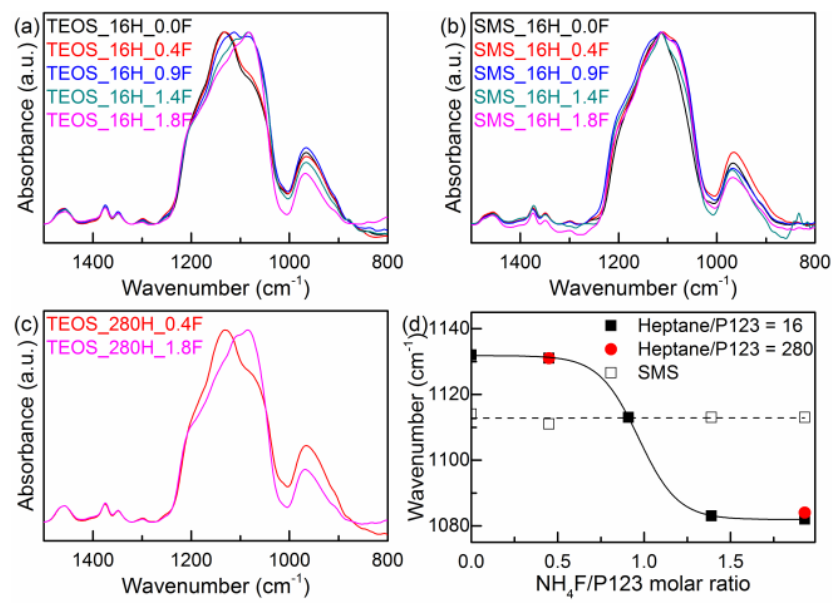

Figure 7. The final ATR spectrum of (a) TEOS_16H_YF, (b) SMS_16H_YF, and (c) TEOS_280H_YF.

(d) shows the shift of the wavelength with the highest absorbance as a function of NH4F concentration.

The effect of $\mathrm{NH}_{4} \mathrm{~F}$ on the silica structure during the silica formation is shown in Figure 8. Figure 8 (a) and (b) show the stage (ii) evolution for $\mathrm{NH}_{4} \mathrm{~F} / \mathrm{P} 123=0.9$ and 1.8 respectively. We note that for the higher $\mathrm{NH}_{4} \mathrm{~F}$ concentrations, cyclic silica species are formed directly after the TEOS hydrolysis, while for lower concentrations, linear structures are formed initially. The band evolution in stage (v) (Figure 8 (c) and (d)) show that the growth of linear silica species $\left(1140 \mathrm{~cm}^{-1}\right)$ is significantly less compared to the six-fold cyclic structure $\left(1070 \mathrm{~cm}^{-1}\right.$ and $\left.1190 \mathrm{~cm}^{-1}\right)$ when the $\mathrm{NH}_{4} \mathrm{~F}$ concentration is increased. When no $\mathrm{NH}_{4} \mathrm{~F}$ is used (Figure 3 (d)), the strongest band is related to linear structures, while for $\mathrm{NH}_{4} \mathrm{~F} / \mathrm{P} 123=0.9$ (Figure 8 (c)) the six-fold cyclic structure is stronger, and finally it is the dominating phase for $\mathrm{NH}_{4} \mathrm{~F} / \mathrm{P} 123=1.8$. It can also be noted that the band at $960 \mathrm{~cm}^{-1}$ decreases with increasing salt content. This indicates that the number of silanols is very much less after the particle formation for the materials with high $\mathrm{NH}_{4} \mathrm{~F}$ concentration.
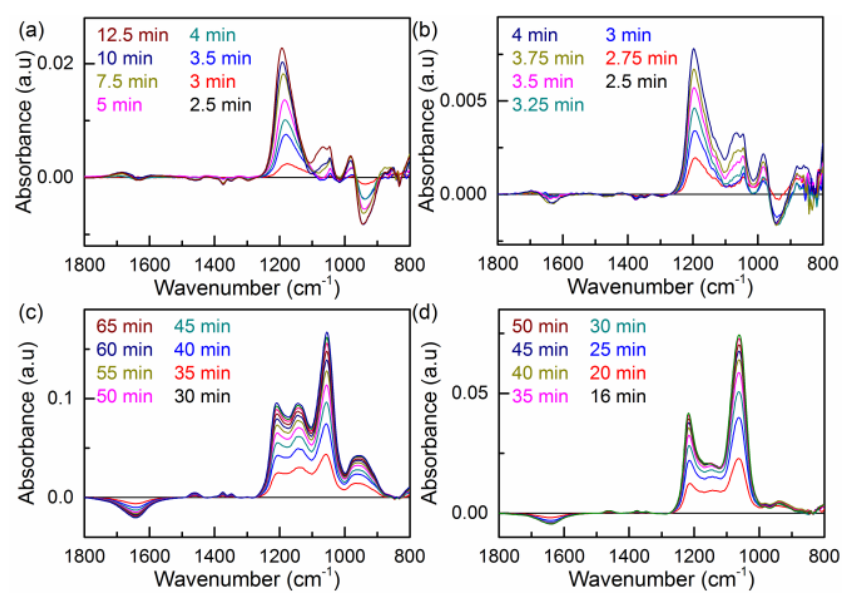
Figure 8. The material evolution in TEOS_16H_0.9F in (a) stage (ii) and (c) stage (v), and TEOS_16H_1.8F in (b) stage (ii) and (d) stage (v).

\section{Discussion}

\section{The formation stages}

From the results presented in Figure 3, there are five stages in the material synthesis when TEOS is used as the silica precursor. During the first two stages, there is no apparent interaction between the silica species and the micelles. Silica oligomers enters the corona and polymerize to small silica clusters without indications of affecting the micelle structure. Sundblom et al..$^{33}$ showed that the micellesilica interaction mainly is enthalpy driven, and that a certain size of the silica species is required for the interaction to occur. This is the reason for the much faster material evolution when SMS is used as the silica precursor. As can be seen in Figure 4 (a), silica clusters are already formed before the precursor is added to the micellar solution. These species are large enough to interact with the micelles, which initiates the micelle elongation and formation of the hexagonal network.

In stage (iii), the silica clusters start to interact with each other and form a network in the micellar corona. At this stage a large variety of silica species are formed. In the end of stage (iii) PPO related bands start to grow. This is due to changes in the hydration of the PPO core of the micelles. Su et al. ${ }^{32}$ showed that the bands at $1374 \mathrm{~cm}^{-1}$ and $1344 \mathrm{~cm}^{-1}$ are very weak for low concentrations of pluronic P104 in aqueous solution, but increase for higher surfactant concentrations. They concluded therefore that the PPO is not hydrated at high surfactant concentrations. This indicates that the water in the corona is expelled when the silica network is formed, which enable methyl group vibrations in the PPO core. These findings correlate well with the EPR study from Ruthstein et al. ${ }^{14}$ who observed a depletion of water in the corona region upon the condensation of the silica network. Flodström et al. ${ }^{13}$ followed the material formation using NMR and observed a broadening in the PO signal upon the micellar elongation from spheres to cylinders. This indicates that it is possible to monitor the micelle shape evolution by observing the PPO related bands in the ATR spectra.

In stage (iv), the rapid growth of silica related bands in combination with the PPO related bands display condensation of silica in the micelle corona. The appearance of Bragg peaks at this stage also shows that elongated micelles aggregate and form the hexagonal structure at this stage. A material with long-range order is needed for diffraction to occur. To achieve long range order, several micelles need to aggregate to form the hexagonal structure. This takes time and causes a delay before Bragg peaks are observed. Stage (iv) proceeds faster for SMS synthesized materials. It is completed in less than 10 min compared to 15-35 min for TEOS materials. This time difference indicates that for TEOS materials, formation of the hexagonal framework is more successive and occurs alongside with micelle elongation due to the continued growth of silica species in the corona, i.e. micelle aggregation is ac- 
companied by condensation of silica walls around each micelle. In the case of SMS, the silica clusters in the corona are initially large, and therefore the main silica condensation is between these large clusters to form the silica walls. The aggregation of micelles needs further time and therefore the intensity of the Bragg peak is growing also in stage (v). The evidence of large silica clusters in the corona already at the beginning of the condensation can explain the thicker silica walls in materials synthesized with SMS.

The final stage is the last silica condensation, where additional silica bonds are formed as the walls between the aggregated micelles densify. At this stage the silica walls surrounding the micelles are mainly formed, and the silicated micelles bind stronger together.

\section{Effect of $\mathrm{NH}_{4} \mathrm{~F}$ on the formation kinetics and silica structure}

From Figure 8, it is clear that $\mathrm{NH}_{4} \mathrm{~F}$ affects which silica species that are formed, especially for TEOS materials. When a higher concentration of $\mathrm{NH}_{4} \mathrm{~F}$ is added, more six-fold cyclic silica species are formed, and the amount of linear structure decreases. This is especially obvious comparing the band intensities in Figure 3 (d), Figure 8 (c) and (d). The fluoride ion increases the coordination number of silicone. Silicone with a higher coordination number is also more reactive and will polymerize faster compared to four-fold silica species. ${ }^{34}$ The rate change in polymerization is clearly observed in Figure 5 , where all stages, except stage (i), become faster in the presence of high $\mathrm{NH}_{4} \mathrm{~F}$ concentrations. The time needed for the formation of the hexagonal framework is in good agreement with previous results where SBA-15 rods were formed within 7 min after the addition of TEOS at a $\mathrm{NH}_{4} \mathrm{~F} / \mathrm{P} 123$ molar ratio of $1.83,{ }^{7}$ and that only minor changes at the mesoscopic range occurred after $30 \mathrm{~min} .{ }^{35}$ The fast polymerization can also be the reason for the difference in particle morphology, where a high $\mathrm{NH}_{4} \mathrm{~F}$ concentration yields more narrow particles. ${ }^{24-25,35}$ The micelles attach through condensation of silanol groups, and as can be seen in Figure 7 and Figure 8, the number of uncondensed silica species, silanols and $\mathrm{Si}-\mathrm{O}^{-}$at $\sim 960 \mathrm{~cm}^{-1}$ decreases with increasing salt concentration.

Figure 7 also shows that $\mathrm{NH}_{4} \mathrm{~F}$ affects the final structure less for SMS materials. The reason for this is again the pre-hydrolysis of the silica precursor, which is made in a $\mathrm{HCl}$ solution without $\mathrm{NH}_{4} \mathrm{~F}$ additions. Therefore, the added silica clusters will have the same structure, and only the surface of these can be affected by the fluoride ions. The $\mathrm{NH}_{4} \mathrm{~F}$ still affects the coordination number on the surface silica, which affects the formation rate of the materials (Figure 5 (b)).

\section{The TEOS hydrolysis rate}

When the TEOS/heptane mixture is added to the micellar solution, an oil-in-water emulsion is formed. The TEOS hydrolysis occurs at the TEOS/water interface, ${ }^{11}$ and therefore the amount of heptane and $\mathrm{NH}_{4} \mathrm{~F}$ affect the hydrolysis rate. When heptane/P123 = 16, the heptane is solvated in the TEOS, and the droplet size is equal independent of $\mathrm{NH}_{4} \mathrm{~F}$, due to the low oil concentration. When larger amounts 
of heptane are used, the TEOS is solvated in the heptane and hydrolyses when it reaches the emulsion droplet surface. When the $\mathrm{NH}_{4} \mathrm{~F}$ concentration increases, the ionic strength of the solution increases, leading to smaller oil droplets. The emulsion with smaller droplets has a higher surface area causing a higher hydrolysis rate.

\section{Conclusions}

We have studied the formation of mesoporous silica at various synthesis compositions using in situ ATR and SAXRD. Five stages in the material formation were identified: TEOS hydrolysis, silica polymerization, siliceous network formation, silica densification, and continued condensation. The fourth stage could be correlated with hexagonal ordering of the micelles. When SMS was used as the silica precursor, the two first stages were not observed due to the pre-hydrolysis of the SMS resulting in that small silica clusters was formed prior to the addition into the micellar solution. A specific size of the silica clusters in the micelle corona is required for the micelle elongation, and hence, materials synthesized from SMS form faster compared to TEOS materials. In the end of stage three, bands related to PPO vibrations in the micellar core start to grow, indicating elongation of the micelles from spheres to cylinders. $\mathrm{NH}_{4} \mathrm{~F}$ affects both the formation kinetics and silica structure due to its ability to change the coordination number of silicone, yielding more six-fold, more reactive, cyclic silica species. The TEOS hydrolysis rate is affected by the amount of heptane and $\mathrm{NH}_{4} \mathrm{~F}$ due to alterations in the oil droplet size.

The study demonstrates that in situ ATR is a powerful tool for monitoring the formation of mesoporous silica, both in terms of formation kinetics and elucidating details in the silica network. Previously, this technique has been neglected due to the strong water contribution. ${ }^{8,19}$ This is the first time that details of the chemical structure of the silica species during the material formation can be observed. The study provides detailed insights into the formation of mesoporous silica and can be used for future fine tuning of the materials characteristics. We envision that the presented method can be used to study doping mechanisms in the silica framework, as well as the formation of other sol-gel synthesized materials.

\section{Acknowledgement}

The authors acknowledge the Swedish research council (Dnr 2015-00624), the competence center FunMat-II financially supported by Vinnova (Grant no 2016-05156), the Swedish Government Strategic Research Area in Materials Science on Functional Materials at Linköping University (Faculty Grant SFO-Mat-LiU \# 2009-00971), Knut and Alice Wallenberg Foundation (contract KAW 
2012.0083), EU's Erasmus-Mundus program DocMASE, and Nanolith Sverige AB for financial support. Parts of this research were carried out at the light source PETRA III at DESY.

\section{Supporting Material}

Reference ATR spectra of P123, ethanol and TEOS, as well as SEM micrographs and physisorption data for selected mesoporous materials are provided. 


\section{References}

1. Rosenholm, J. M.; Zhang, J.; Linden, M.; Sahlgren, C., Mesoporous silica nanoparticles in tissue engineering--a perspective. Nanomedicine (Lond) 2016, 11 (4), 391-402.

2. Melde, B.; Johnson, B.; Charles, P., Mesoporous Silicate Materials in Sensing. Sensors 2008, 8 (8),

5202.

3. Liang, J.; Liang, Z.; Zou, R.; Zhao, Y., Heterogeneous Catalysis in Zeolites, Mesoporous Silica, and Metal-Organic Frameworks. Advanced Materials 2017, 29 (30), 1701139-n/a.

4. Zhao, D.; Feng, J.; Huo, Q.; Melosh, N.; Fredrickson, G. H.; Chmelka, B. F.; Stucky, G. D., Triblock Copolymer Syntheses of Mesoporous Silica with Periodic 50 to 300 Angstrom Pores. Science 1998, 279 (5350), 548-552.

5. Kjellman, T.; Reichhardt, N.; Sakeye, M.; Smatt, J. H.; Lindn, M.; Alfredsson, V., Independent finetuning of the intrawall porosity and primary mesoporosity of SBA-15. Chemistry of Materials 2013, 25 (9), 1989-1997.

6. Brodie-Linder, N.; Dosseh, G.; Alba-Simonesco, C.; Audonnet, F.; Impéror-Clerc, M., SBA-15 synthesis: Are there lasting effects of temperature change within the first 10min of TEOS polymerization? Materials Chemistry and Physics 2008, 108 (1), 73-81.

7. Björk, E. M.; Söderlind, F.; Odén, M., Single-pot synthesis of ordered mesoporous silica films with unique controllable morphology. Journal of Colloid and Interface Science 2014, 413, 1-7.

8. Kjellman, T.; Alfredsson, V., The use of in situ and ex situ techniques for the study of the formation mechanism of mesoporous silica formed with non-ionic triblock copolymers. Chem. Soc. Rev. 2013, 42 (9), 3777-3791.

9. Blin, J. L.; Imperor-Clerc, M., Mechanism of self-assembly in the synthesis of silica mesoporous materials: in situ studies by X-ray and neutron scattering. Chem. Soc. Rev. 2013, 42 (9), 4071-4082.

10. Imperor-Clerc, M.; Manet, S.; Grillo, I.; Durand, D.; Khodakov, A.; Zholobenko, V., SANS study of the mechanisms and kinetics of the synthesis of mesoporous materials from micelles of tri-block copolymers.

Zeolites and Related Materials: Trends, Targets and Challenges, Proceedings of the 4th International Feza Conference 2008, 174, 805-810.

11. Manet, S.; Schmitt, J.; Imperor-Clerc, M.; Zholobenko, V.; Durand, D.; Oliveira, C. L. P.; Pedersen, J. S.; Gervais, C.; Baccile, N.; Babonneau, F.; Grillo, I.; Meneau, F.; Rochas, C., Kinetics of the Formation of 2DHexagonal Silica Nanostructured Materials by Nonionic Block Copolymer Templating in Solution. J. Phys. Chem. B 2011, 115 (39), 11330-11344.

12. Baccile, N.; Laurent, G.; Bonhomme, C.; Innocenzi, P.; Babonneau, F., Solid-state NMR characterization of the surfactant-silica interface in templated silicas: Acidic versus basic conditions. Chem. Mat. 2007, 19 (6), 1343-1354.

13. Flodstrom, K.; Wennerstrom, H.; Alfredsson, V., Mechanism of mesoporous silica formation. A timeresolved NMR and TEM study of silica-block copolymer aggregation. Langmuir 2004, 20 (3), 680-688.

14. Ruthstein, S.; Frydman, V.; Goldfarb, D., Study of the initial formation stages of the mesoporous material SBA-15 using spin-labeled block co-polymer templates. J. Phys. Chem. B 2004, 108 (26), $9016-9022$.

15. Ruthstein, S.; Schmidt, J.; Kesselman, E.; Talmon, Y.; Goldfarb, D., Resolving intermediate solution structures during the formation of mesoporous SBA-15. Journal of the American Chemical Society 2006, 128 (10), 3366-3374.

16. Imperor-Clerc, M.; Grillo, I.; Khodakov, A. Y.; Durand, D.; Zholobenko, V. L., New insights into the initial steps of the formation of SBA-15 materials: an in situ small angle neutron scattering investigation. Chem. Commun. 2007, (8), 834-836.

17. Zholobenko, V. L.; Khodakov, A. Y.; Imperor-Clerc, M.; Durand, D.; Grillo, I., Initial stages of SBA15 synthesis: An overview. Adv. Colloid Interface Sci. 2008, 142 (1-2), 67-74.

18. Alfredsson, V.; Wennerstrom, H., The Dynamic Association Processes Leading from a Silica Precursor to a Mesoporous SBA-15 Material. Accounts Chem. Res. 2015, 48 (7), 1891-1900.

19. Baccile, N.; Teixeira, C. V.; Amenitsch, H.; Villain, F.; Linden, M.; Babonneau, F., Time-resolved in situ Raman and small-angle X-ray diffraction experiments: From silica-precursor hydrolysis to development of mesoscopic order in SBA-3 surfactant-templated silica. Chem. Mat. 2008, 20 (3), 1161-1172.

20. Tejedor-Tejedor, M. I.; Paredes, L.; Anderson, M. A., Evaluation of ATR-FTIR Spectroscopy as an "in Situ" Tool for Following the Hydrolysis and Condensation of Alkoxysilanes under Rich H2O Conditions. Chem. Mat. 1998, 10 (11), 3410-3421.

21. Innocenzi, P.; Malfatti, L.; Carboni, D.; Takahashi, M., Sol-to-Gel Transition in Fast Evaporating Systems Observed by in Situ Time-Resolved Infrared Spectroscopy. ChemPhysChem 2015, 16 (9), 1933-1939. 22. Malfatti, L.; Innocenzi, P., Sol-gel chemistry: from self-assembly to complex materials. J. Sol-Gel Sci. Technol. 2011, 60 (3), 226-235. 
23. Zhao, J.; Kalanyan, B.; Barton, H. F.; Sperling, B. A.; Parsons, G. N., In Situ Time-Resolved Attenuated Total Reflectance Infrared Spectroscopy for Probing Metal-Organic Framework Thin Film Growth. Chem. Mat. 2017, 29 (20), 8804-8810.

24. Björk, E. M.; Söderlind, F.; Odén, M., Tuning the Shape of Mesoporous Silica Particles by Alterations in Parameter Space: From Rods to Platelets. Langmuir 2013, 29 (44), 13551-13561.

25. Yang, Y.; Yang, H.; Liu, L.; Li, T.; Yuan, H.; Ni, C., Effects of fluoride ion on the formation of earthworm-like mesoporous silica. Journal of the American Ceramic Society 2017, 100 (6), 2502-2515.

26. Cao, L.; Kruk, M., Facile method to synthesize platelet SBA-15 silica with highly ordered large mesopores. Journal of Colloid and Interface Science 2011, 361 (2), 472-476.

27. Atakan, A.; Mäkie, P.; Söderlind, F.; Keraudy, J.; Björk, E. M.; Odén, M., Synthesis of a Cu-infiltrated Zr-doped SBA-15 catalyst for CO2 hydrogenation into methanol and dimethyl ethert. Physical Chemistry Chemical Physics 2017, 19 (29), 19139-19149.

28. Sun, J.; Zhang, H.; Ma, D.; Chen, Y.; Bao, X.; Klein-Hoffmann, A.; Pfander, N.; Su, D. S., Alkanesassisted low temperature formation of highly ordered SBA-15 with large cylindrical mesopores. Chem. Commun. 2005, (42), 5343-5345.

29. Manet, S.; Lecchi, A.; Impéror-Clerc, M.; Zholobenko, V.; Durand, D.; Oliveira, C. L. P.; Pedersen, J. S.; Grillo, I.; Meneau, F.; Rochas, C., Structure of Micelles of a Nonionic Block Copolymer Determined by SANS and SAXS. The Journal of Physical Chemistry B 2011, 115 (39), 11318-11329.

30. Fulvio, P. F.; Pikus, S.; Jaroniec, M., Short-time synthesis of SBA-15 using various silica sources. Journal of Colloid and Interface Science 2005, 287 (2), 717-720.

31. Zhou, Y. Y.; Li, X. X.; Chen, Z. X., Rapid synthesis of well-ordered mesoporous silica from sodium silicate. Powder Technology 2012, 226, 239-245.

32. Su, Y.-1.; Wang, J.; Liu, H.-Z., Melt, Hydration, and Micellization of the PEO-PPO-PEO Block Copolymer Studied by FTIR Spectroscopy. Journal of Colloid and Interface Science 2002, 251 (2), 417-423.

33. Sundblom, A.; Oliveira, C. L. P.; Pedersen, J. S.; Palmqvist, A. E. C., On the Formation Mechanism of Pluronic-Templated Mesostructured Silica. Journal of Physical Chemistry C 2010, 114 (8), 3483-3492.

34. Brinker, C. J., Hydrolysis and condensation of silicates: Effects on structure. J. Non-Cryst. Solids 1988, $100(1), 31-50$.

35. Johansson, E. M.; Ballem, M. A.; Córdoba, J. M.; Odén, M., Rapid Synthesis of SBA-15 Rods with Variable Lengths, Widths, and Tunable Large Pores. Langmuir 2011, 27, 4994-4999.

36. Kimura, N.; Umemura, J.; Hayashi, S., Polarized FT-IR Spectra of Water in the Middle Phase of Triton X100-Water System. Journal of Colloid and Interface Science 1996, 182 (2), 356-364.

37. Rubio, F.; Rubio, J.; Oteo, J. L., A FT-IR Study of the Hydrolysis of Tetraethylorthosilicate (TEOS). Spectroscopy Letters 1998, 31 (1), 199-219.

38. Guo, C.; Liu, H.; Wang, J.; Chen, J., Conformational Structure of Triblock Copolymers by FT-Raman and FTIR Spectroscopy. Journal of Colloid and Interface Science 1999, 209 (2), 368-373.

39. Innocenzi, P., Infrared spectroscopy of sol-gel derived silica-based films: a spectra-microstructure overview. J. Non-Cryst. Solids 2003, 316 (2-3), 309-319.

40. Lenza, R. F. S.; Vasconcelos, W. L., Structural evolution of silica sols modified with formamide. Materials Research 2001, 4, 175-179.

41. Wang, S.; Wang, D. K.; Smart, S.; Diniz da Costa, J. C., Ternary Phase-Separation Investigation of SolGel Derived Silica from Ethyl Silicate 40. Scientific Reports 2015, 5, 14560. 


\section{Figure captions}

Figure 1. Illustration of the setup used for in situ SAXRD and ATR measurements.

Figure 2. ATR spectra of the synthesis solution at (a) $t=0-5 \mathrm{~min}$, and the evolution of bands related to the hydrolysis of TEOS for (b) TEOS_16H_0.0F, (c) TEOS_16H_0.9F, (d) TEOS_16H_1.8F, (e) TEOS_280H_0.4F, and (f) TEOS_280H_1.8F.

Figure 3. Differential ATR spectra for TEOS_16H_0.0F showing the band evolution during the time periods: (a) 2.5-50 min, (b) 30-70 min, (c) 50-120 min, and (d) 105-150 min.

Figure 4. Differential ATR spectra for SMS_16H_0.4F showing the band evolution during the time periods: (a) $0-4.7 \mathrm{~min}$, (b) $1-6.1 \mathrm{~min}$, (c) $3-11 \mathrm{~min}$, and (d) $10-28 \mathrm{~min}$.

Figure 5. The different stages during the silica formation as a function of $\mathrm{NH}_{4} \mathrm{~F}$ concentration for (a) TEOS and (b) SMS as silica precursors.

Figure 6. The correlation between the silica formation and evolution of the 100 Bragg peak in (a)

TEOS_16H_0.4F, (b) SMS_16H_0.4F, (c) TEOS_16H_0.9F, (d) SMS_16H_0.9F, and (e) TEOS_16H_1.8F.

Figure 7. The final ATR spectrum of (a) TEOS_16H_YF, (b) SMS_16H_YF, and (c) TEOS_280H_YF. (d) shows the shift of the wavelength with the highest absorbance as a function of NH4F concentration.

Figure 8. The material evolution in TEOS_16H_0.9F in (a) stage (ii) and (c) stage (v), and TEOS_16H_1.8F in (b) stage (ii) and (d) stage (v). 
Table 1. Assignments of FTIR bands of TEOS, ethanol, and P123

\begin{tabular}{|c|c|c|c|}
\hline TEOS $^{\mathrm{a}}$ & Ethanol $^{b}$ & $\mathrm{P} 123^{\mathrm{c}}$ & Assignment \\
\hline & 3320 & & O-H stretch \\
\hline 2976 & 2973 & 2971 & $\mathrm{C}-\mathrm{H}$ asym. stretch \\
\hline 2929 & 2929 & 2928 & C-H asym. stretch \\
\hline \multirow[t]{2}{*}{2890} & 2882 & 2890 & C-H asym. stretch \\
\hline & & 1458 & $\mathrm{CH}_{2}$ scissor \\
\hline \multirow[t]{2}{*}{1390} & 1380 & 1374 & $\mathrm{CH}_{3}$ symmetric deformation \\
\hline & & 1344 & $\mathrm{CH}_{2}$ wag \\
\hline \multirow[t]{3}{*}{1295} & & & $\mathrm{CH}_{2}$ twist \\
\hline & & 1281 & $\mathrm{CH}_{2}$ twist \\
\hline & & 1242 & $\mathrm{CH}_{2}$ twist \\
\hline \multirow[t]{3}{*}{1168} & & & C-H rock \\
\hline & & 1142 & C-O-C stretch, C-C stretch \\
\hline & & 1108 & $\mathrm{C}-\mathrm{O}-\mathrm{C}$ stretch \\
\hline 1103 & & & $\mathrm{CH}_{3}$ rock \\
\hline \multirow[t]{4}{*}{1077} & 1088 & & C-C stretch \\
\hline & & 1063 & $\mathrm{C}-\mathrm{O}$ asym. stretch, $\mathrm{CH}_{2}$ rock \\
\hline & 1048 & & C-O sym. stretch \\
\hline & & 1015 & $\mathrm{CH}_{3}$ vibration \\
\hline \multirow[t]{4}{*}{961} & & 962 & $\mathrm{C}-\mathrm{O}$ stretch, $\mathrm{CH}_{2}$ rock \\
\hline & & 931 & $\mathrm{C}-\mathrm{H}$ vibration \\
\hline & 880 & & $\mathrm{CH}_{3}$ or $\mathrm{CH}_{2}$ deformation \\
\hline & & 843 & $\mathrm{CH}_{2}$ rock \\
\hline
\end{tabular}

${ }^{\text {a }}$ Assignment based on $\operatorname{Ref}^{20,32,36}$

${ }^{\mathrm{b}}$ Assignment based on $\operatorname{Ref}{ }^{20,37}$

${ }^{\mathrm{c}}$ Assignment based on $\operatorname{Ref}{ }^{32,36,38}$ 
Table 2. Assignment of silica related bands

\begin{tabular}{ll}
\hline $\begin{array}{l}\text { Wavenumber } \\
\left(\mathrm{cm}^{-1}\right)\end{array}$ & Assignment $^{39-41}$ \\
\hline 1250 & LO $_{3}$ asym. stretching \\
1200 & Si-O-Si asym. stretch 6-ring \\
1147 & Si-O-Si asym. stretch linear struc- \\
& ture \\
1100 & Si-O-Si sym. stretch linear struc- \\
& ture \\
1086 & Si-O-Si sym. stretch cyclic struc- \\
& ture \\
1070 & TO ${ }_{3}$ asym. stretch 6-ring \\
1035 & Si-O-Si chain \\
960 & Si-OH \\
920 & Si-O- open rings \\
&
\end{tabular}


Supporting Material

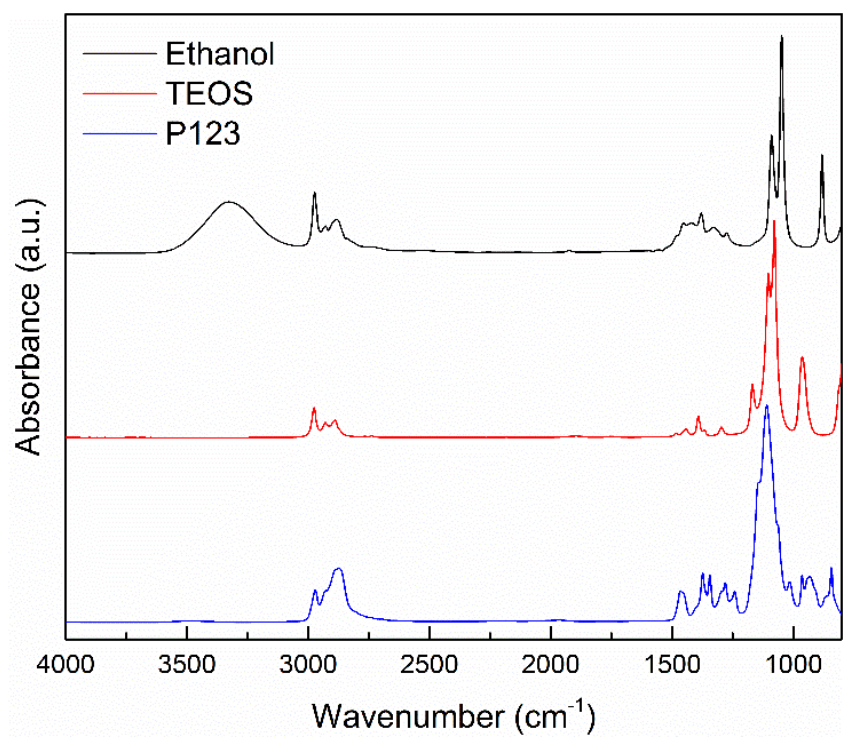

Figure S1. Reference ATR spectra of ethanol, TEOS and P123. 

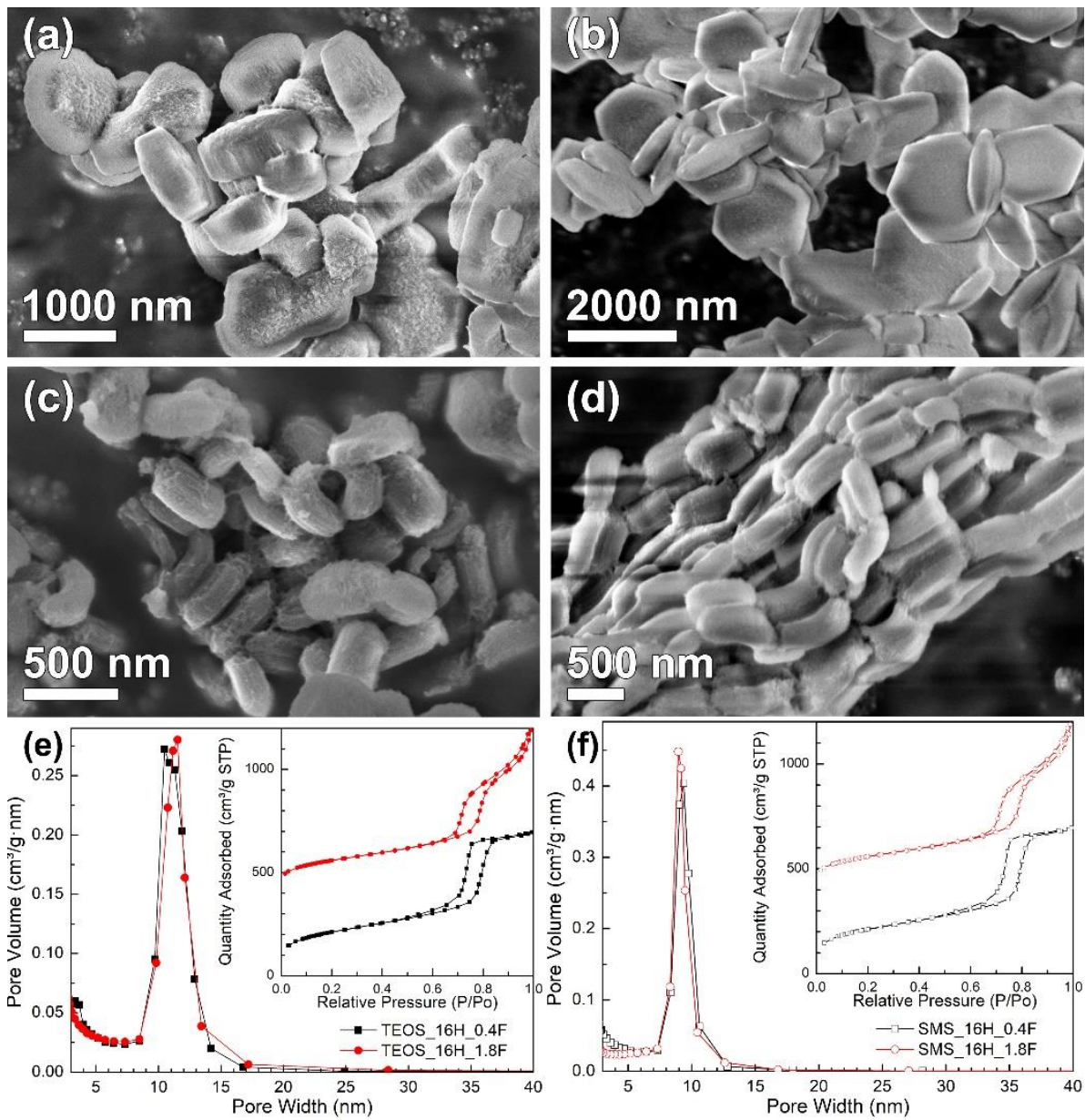

Figure S2. SEM micrographs of (a) TEOS_16H_0.4F, (b) SMS_16H_0.4F, (c) TEOS_16H_1.8F, and (d) SMS_16H_1.8F, showing that the particle morphology is similar independent of silica precursor. Physisorption iosotherms and pore size distributions of materials synthesized with (e) TEOS and (f) SMS, showing the cylindrical pore structure of the materials.

The SEM micrographs were taken using a Leo 1550 Gemini Scanning Electron Microscope operated at $3 \mathrm{kV}$ and a working distance of 3-5 mm. $\mathrm{N}_{2}$ physisorption isotherms were recorded on a Micromeritics ASAP2020 at $77 \mathrm{~K}$. The pore size distributions were calculated using the KJS-method on the adsorption isotherms. 